\title{
Intracranial pressure monitoring among children with severe traumatic brain injury
}

\author{
Aziz S. Alali, MD, PhD,1-3 David Gomez, MD, PhD, 1,3 Chethan Sathya, MD,1,3,4 \\ Randall S. Burd, MD, PhD, ${ }^{5}$ Todd G. Mainprize, MD, ${ }^{6}$ Richard Moulton, MD, ${ }^{2}$ \\ Richard A. Falcone Jr., MD, MPH, ${ }^{7}$ Charles de Mestral, MD, PhD, ${ }^{1,3}$ and \\ Avery Nathens, MD, PhD, MPH ${ }^{1,3,4,8}$
}

${ }^{1}$ Sunnybrook Research Institute, Sunnybrook Health Sciences Center, Toronto; ${ }^{2}$ Division of Neurosurgery, University of Ottawa; ${ }^{3}$ Department of Surgery, University of Toronto; ${ }^{4}$ Institute of Health Policy, Management and Evaluation, University of Toronto, Ontario, Canada; ${ }^{5}$ Division of Trauma and Burn Surgery, Children's National Medical Center, Washington, DC; ${ }^{6}$ Division of Neurosurgery, Sunnybrook Health Sciences Center, University of Toronto, Ontario, Canada; ${ }^{7}$ Division of Pediatric Surgery, Cincinnati Children's Hospital Medical Center, Cincinnati, Ohio; and ${ }^{8}$ Department of Surgery, Sunnybrook Health Sciences Center, Toronto, Ontario, Canada

OBJECT Well-designed studies linking intracranial pressure (ICP) monitoring with improved outcomes among children with severe traumatic brain injury (TBI) are lacking. The main objective of this study was to examine the relationship between ICP monitoring in children and in-hospital mortality following severe TBI.

METHODS An observational study was conducted using data derived from 153 adult or mixed (adult and pediatric) trauma centers participating in the American College of Surgeons (ACS) Trauma Quality Improvement Program (TQIP) and 29 pediatric trauma centers participating in the pediatric pilot TQIP between 2010 and 2012. Random-intercept multilevel modeling was used to examine the association between ICP monitoring and in-hospital mortality among children with severe $\mathrm{TBI} \leq 16$ years of age after adjusting for important confounders. This association was evaluated at the patient level and at the hospital level. In a sensitivity analysis, this association was reexamined in a propensity-matched cohort.

RESULTS A total of 1705 children with severe TBI were included in the study cohort. The overall in-hospital mortality was $14.3 \%$ of patients $(n=243)$, whereas the mortality of the 273 patients $(16 \%)$ who underwent invasive ICP monitoring was $11 \%(n=30)$. After adjusting for patient- and hospital-level characteristics, ICP monitoring was associated with lower in-hospital mortality (adjusted OR 0.50; $95 \% \mathrm{Cl} 0.30-0.85 ; p=0.01$ ). It is possible that patients who were managed with ICP monitoring were selected because of an anticipated favorable or unfavorable outcome. To further address this potential selection bias, the analysis was repeated with the hospital-specific rate of ICP monitoring use as the exposure. The adjusted OR for death of children treated at high ICP-use hospitals was 0.49 compared with those treated at low ICP-use hospitals (95\% Cl 0.31-0.78; $p=0.003$ ). Variations in ICP monitoring use accounted for $15.9 \%$ of the interhospital variation in mortality among children with severe TBI. Similar results were obtained after analyzing the data using propensity score-matching methods.

CONCLUSIONS In this observational study, ICP monitoring use was associated with lower hospital mortality at both the patient and hospital levels. However, the contribution of variable ICP monitoring rates to interhospital variation in pediatric TBI mortality was modest.

http://thejns.org/doi/abs/10.3171/2015.3.PEDS14507

KEY WORDS head injury; intracranial pressure; multilevel analysis; propensity score; traumatic brain injury; trauma

ABBREVIATIONS ACS = American College of Surgeons; AIS = Abbreviated Injury Scale; GCS = Glasgow Coma Scale; ICC = intraclass correlation coefficient; ICD-9-CM = International Classification of Diseases, Ninth Revision, Clinical Modification; ICP = intracranial pressure; MOR = median odds ratio; PCV = proportional change in variance; TBI = traumatic brain injury; TQIP = Trauma Quality Improvement Program.

SUBMITTED September 21, 2014. ACCEPTED March 25, 2015.

INCLUDE WHEN CITING Published online August 14, 2015; DOI: 10.3171/2015.3.PEDS14507. 
$\mathrm{T}$ RaUMATIC brain injury (TBI) is the leading cause of injury-related death among children and adolescents in industrialized countries. ${ }^{14}$ Among children 0-14 years old in the US, TBI results in an estimated 400,000 emergency department visits, 29,000 hospitalizations, and 3,000 deaths every year. ${ }^{24}$ Furthermore, children sustaining TBI may suffer long-term cognitive and physical disabilities, particularly with severe TBIs. ${ }^{3}$

The primary brain injury initiates a cascade of intraand extracellular processes, which mediate a delayed phase of secondary injury that evolves over the minutes, hours, and days after the initial injury. ${ }^{11,17,19}$ Elevated intracranial pressure (ICP) is a common pathway for multiple secondary injury processes, which can further damage the exquisitely sensitive brain. The underlying conditions that mediate high ICP following TBI include increased CSF volume, increased cerebral blood volume, cytotoxic edema, and blood-brain barrier damage associated with vasogenic edema. ${ }^{38}$ Because high ICP following severe TBI is both difficult to diagnose and associated with poor outcome, continuous ICP monitoring via an invasive tool might facilitate the early detection of elevated ICP, which can enable prompter treatment to control the rising ICP.

Invasive ICP monitoring in pediatric patients first became part of the Brain Trauma Foundation guidelines for the management of severe TBI in children in 2003. ${ }^{1,22}$ The Level III recommendation of ICP monitoring use was based on the high incidence of intracranial hypertension among children with severe TBI and the strong association between high ICP and poor neurological outcome..$^{2,8,18,22}$ Well-designed studies linking ICP monitoring use to better outcomes in children are lacking. The dearth of supporting evidence might explain the reported wide variability in ICP monitoring use among children with severe TBI. ${ }^{9}$ Both the significance of this variability in managing pediatric TBI and its impact on outcome are unclear.

To address these evidence gaps, we conducted an observational study that aims to 1) examine the association between ICP monitoring and in-hospital mortality following severe TBI at the patient level; 2) examine the association between the hospital-specific rate of ICP monitoring use among children with severe TBI and hospital TBI-related mortality; and 3) determine the extent of interhospital variation in pediatric TBI mortality and the contribution of the hospital-specific rate of ICP use to this variability.

\section{Methods}

\section{Study Design}

This was a retrospective cohort study that aimed to examine the relationship between ICP monitoring and inhospital mortality. We first evaluated this relationship at the patient level. Because the distribution of unmeasured confounding is probably similar at different hospitals, we also evaluated this relationship at the hospital level. Finally, we examined the extent of interhospital variation in pediatric TBI mortality and the contribution of different rates of ICP monitoring use to this variation. The study was approved by the Research Ethics Board at Sunnybrook Health Sciences Center (Toronto, Ontario, Canada).

\section{Data Source}

We used data derived from 1) 153 hospitals designated as adult trauma centers or as both adult and pediatric (i.e., mixed) trauma centers participating in the American College of Surgeons (ACS) Trauma Quality Improvement Program (TQIP); and 2) 29 hospitals designated as pediatric trauma centers participating in the pediatric pilot TQIP. The TQIP was established to provide Level I and II trauma centers with an opportunity to compare their risk-adjusted outcomes with peer centers to measure, understand, and continually improve the quality of their performance in trauma care. ${ }^{16,37}$ Inclusion into the TQIP requires an International Classification of Diseases, Ninth Revision, Clinical Modification (ICD-9-CM) diagnosis code of 800-959, excluding the late effects of trauma (905-909). ${ }^{16,37}$ More than 100 patient- and hospital-level variables are recorded, including patient demographic data; comorbid illnesses; injury mechanism, severity, and characteristics; physiological variables on admission; inhospital procedures; complications; and mortality. ${ }^{16,37}$ Although the ACS oversees the program, the authors are responsible for the analyses and findings presented herein.

\section{Eligibility Criteria}

We identified patients 16 years of age or younger who were hospitalized between January 1, 2010, and December 31, 2012. To be consistent with the Brain Trauma Foundation guidelines for invasive ICP monitoring, we only included patients with severe TBI, defined as a total Glasgow Coma Scale (GCS) score $\leq 8$. To ensure homogeneity of the cohort, we excluded the following: patients with minor or moderate head injuries (defined as Abbreviated Injury Scale [AIS] < 3 for the "Head" body region), patients who are unlikely to survive with or without treatment (defined as unsurvivable TBI [Head AIS =6]), patients with penetrating TBI, patients with significant injuries in other body regions (defined as AIS > 2), and patients who were dead on arrival to the emergency department.

\section{Exposure}

Invasive ICP monitoring was the exposure of interest and was defined using one of the following ICD-9-CM codes: insertion of probe or catheter for ICP monitoring (01.10), insertion of probe or catheter for monitoring partial pressure of brain oxygen (01.16), insertion of probe or catheter for monitoring brain temperature (01.17), or insertion of external ventricular drain (02.21).

\section{Outcome Measure}

The outcome measure for this study was the odds of inhospital death following TBI. Variation between trauma centers in recording discharges to hospice care as deaths rather than survivors has been previously shown, and this variation might distort the actual hospital performance. ${ }^{23}$ For this reason, all discharges to hospice care were considered as in-hospital deaths in our study.

\section{Covariates}

The following patient-level covariates were considered for inclusion into our adjusted analyses: age, sex, race, vi- 
tal signs on admission including the presence of systolic hypotension (defined as a systolic blood pressure less than the 5th percentile for age ${ }^{21}$ ), GCS motor score, Head AIS score, injury mechanism, type of intracranial lesion, and insurance status. We used AIS predot codes (1998 version $)^{13}$ to define the different types of intracranial lesions (Table S1 in the Supplementary Appendix).

Several hospital-level characteristics might influence the process-outcome relationship among the pediatric TBI population. In our adjusted analyses, we considered the following variables: ACS or state trauma center designation level (Level I or II), pediatric trauma center designation (pediatric trauma center designation only, adult trauma center designation only, or both), number of hospital beds, teaching status, hospital type (nonprofit or forprofit), and volume of pediatric patients with severe TBI per hospital during the study period (divided into quartiles).

The covariates included in the final models were selected using the change in estimate approach..$^{31}$ The final models included covariates that changed the estimate of the exposure by $\geq 10 \%$ in either direction. ${ }^{31}$ We tested for multicollinearity within each model using variance of inflation factor and tolerance statistic. ${ }^{32}$ For the patient-level analysis, the final model included the following covariates: age, presence of hypotension on admission (defined as a systolic blood pressure less than the 5 th percentile for age $^{5}$ ), GCS motor score, Head AIS score, injury mechanism, type of intracranial lesion (i.e., epidural hematoma, subdural hematoma, traumatic subarachnoid hemorrhage, intracerebral mass lesion, brainstem/cerebellar mass lesion, and compressed/absent basal cisterns), and whether the patient was transferred from another institution. Hospital-level characteristics included in the final model were pediatric trauma center designation (pediatric trauma center designation only, adult trauma center designation only, or both) and volume of pediatric severe TBI per hospital during the study period (divided into quartiles). For the hospital-level analysis, the final model included the following covariates: age, presence of hypotension on admission, GCS motor score, Head AIS score, injury mechanism, type of intracranial lesion, whether the patient was transferred from another institution, and insurance status. Hospital-level characteristics included in the final model were pediatric trauma center designation (pediatric trauma center designation only, adult trauma center designation only, or both), and volume of pediatric severe TBI per hospital during the study period (divided into quartiles).

\section{Statistical Analysis}

We compared the exposure and control groups using standardized differences rather than $\mathrm{p}$ values. Standardized differences were calculated by dividing differences between groups by the pooled SD of the 2 groups. ${ }^{27}$ The advantage of using standardized differences as an alternative to traditional significance testing is that they provide a sense of the relative magnitude of differences without being sensitive to sample size. ${ }^{7,27}$ Standardized differences $>0.1$ are typically considered meaningful. ${ }^{7,27}$

We used 2 random-intercept multilevel logistic regression models to examine the adjusted association between
ICP monitoring use and in-hospital mortality. The exposure for the first model was ICP monitoring as a patientlevel variable. To determine whether the association between ICP monitoring and mortality varied with age, we tested for the potential interaction between ICP monitoring and age. In the second model, hospitals were divided into 2 groups based on their rates of ICP monitoring use among children with severe TBI. Hospitals with a high rate of ICP use (defined as a rate of ICP use $>$ the median) were considered the exposure group, and hospitals with a low rate of ICP use ( $\leq$ the median) served as the control group. For each model, we estimated discrimination by using the c-statistic, and we evaluated calibration by using observed-versus-predicted plots. We quantified the proportion of variance explained by each model by using the squared Pearson correlation between observed and expected outcomes.

To measure the extent of interhospital variation in pediatric TBI mortality, we used the median odds ratio (MOR) rather than intraclass correlation coefficient (ICC). The MOR provides more interpretable information than ICC in the case of multilevel modeling of binary outcomes. ${ }^{25,28}$ The MOR is the median value obtained by comparing the adjusted odds of death if the same individual was admitted to one randomly selected hospital as opposed to another. The MOR is always $\geq 1$ (there is no significant interhospital variation if MOR $=1$ ) because it compares higher- versus lower-ranked hospitals..$^{25,40}$ In contrast to ICC, MOR can be directly compared against the ORs of patient-level variables. ${ }^{25}$ In addition, MOR is statistically independent of the prevalence of the outcome of interest. ${ }^{28}$

The proportion of interhospital variance in mortality among children with severe TBI explained by variable hospital-specific ICP monitoring rates was calculated by using the proportional change in variance (PCV) as follows: PCV $=\left[\left(\mathrm{V}_{1}-\mathrm{V}_{2}\right) \div \mathrm{V}_{1}\right] \times 100 .{ }^{29} \mathrm{~V}_{1}$ is the interhospital variation calculated by using a multilevel model that lacks the hospital-specific rate of ICP monitoring use, and $\mathrm{V}_{2}$ is the interhospital variation calculated by using the same model after adding the hospital-specific rate of ICP monitoring use.

In a sensitivity analysis, we reanalyzed the data by using the propensity score-matching method. By matching subjects based on their likelihood to receive ICP monitoring, propensity score matching has the potential to match and compare patients for whom there was more decision uncertainty regarding assignment to the exposure (i.e., ICP monitoring) group versus the control (no ICP monitoring) group. ${ }^{6}$ First, propensity scores to estimate the probability (based on patient and injury characteristics) that patients would be selected to undergo ICP monitoring were calculated by using logistic regression. Then, we used a 1-to-1 matching technique without replacement to match each exposed patient (managed with ICP monitoring) to an unexposed patient (managed without ICP monitoring) within $0.2 \mathrm{SD}$ of the logit of the propensity score. ${ }^{5,34}$ After matching, the covariate balance was assessed using standardized differences, with a standardized difference $<0.1$ indicating adequate balance. ${ }^{4,6}$ We used a structured iterative approach to refine the logistic regression model that was used to derive propensity scores to achieve balance 
of covariates within the matched pairs. ${ }^{6}$ Finally, we compared the proportion of deaths between the exposure and control groups by using McNemar's test to account for the matched nature of the data. ${ }^{4,6}$ More details are provided in the Supplementary Appendix.

Multiple imputation methods, based on previously established techniques, ${ }^{33}$ were used to estimate the missing GCS motor scores (1.7\%) and systolic blood pressure values $(2.6 \%)$. All analyses were performed using SAS software version 9.3 (SAS Institute). Statistical significance was defined by a 2-tailed significance level of 0.05 .

\section{Results}

The study cohort consisted of 1705 children with severe TBI who were admitted to 1 of 182 Level I or II trauma centers between January 2010 and December 2012. The overall in-hospital mortality was $14.3 \%(\mathrm{n}=243)$. Two hundred seventy-three patients $(16 \%)$ underwent invasive ICP monitoring, with a mortality rate of $11 \%(n=30)$.

In contrast to children who were managed without ICP monitoring, the ICP-monitored group sustained more severe injuries (as measured by Head AIS), and were more likely to have subdural hematoma, traumatic subarachnoid hemorrhage, intracerebral mass lesions, cerebellar or brainstem injuries, and compressed or absent basal cisterns (Table 1). Conversely, children in the non-ICPmonitored group were more likely to sustain fall-related injuries, present with hypotension, and be cared for at pediatric trauma centers, high-volume hospitals, or university hospitals.

We ranked hospitals based on their rates of ICP monitoring use among children with severe TBI. Based on the median rate of hospital-specific ICP monitoring use (14\%), we divided the hospitals into 2 groups: high and low ICP-use groups. Relative to high ICP-use hospitals, low ICP-use hospitals were more likely to be pediatric trauma centers and university hospitals, and they were more likely to care for adolescents and those who experienced injuries from motor vehicle collisions (Table 2). The overall mortality was $12.8 \%$ of patients $(n=122)$ in the high ICP-use hospitals and $16.2 \%(\mathrm{n}=121)$ in the low ICP-use hospitals.

\section{Patient-Level Relationship Between ICP Monitoring and Mortality}

After adjusting for patient- and hospital-level characteristics, ICP monitoring was associated with lower inhospital mortality (adjusted OR $0.50 ; 95 \%$ CI $0.30-0.85$; $p=0.01)$. No significant interaction was found between ICP monitoring and age $(\mathrm{p}=0.19)$, hospital type (pediatric vs adult vs mixed) $(\mathrm{p}=0.68)$, or teaching status (university vs community vs nonteaching) $(\mathrm{p}=0.32)$. The multilevel model had good discrimination $(\mathrm{c}$-statistic $=0.93)$ and calibration (based on the observed-vs-predicted plot).

\section{Hospital-Level Relationship Between ICP Monitoring and Mortality}

Using multilevel logistic regression, the adjusted OR for death of children treated at high ICP-use hospitals was 0.49 compared with those treated at low ICP-use hospitals
(95\% CI 0.31-0.78; $\mathrm{p}=0.003$ ). The model had good discrimination (c-statistic $=0.94)$ and calibration (based on observed-vs-predicted plot), and it explained $68.8 \%$ of the observed interhospital variation in mortality among children with severe TBI.

To measure the extent of interhospital variation in pediatric TBI mortality, we calculated the MOR. After adjusting for patient and hospital characteristics, the MOR for in-hospital death following severe TBI in children across different hospitals was 1.62. That is, the median odds of dying following severe TBI were 1.62 -fold higher if the same child was admitted to one randomly selected hospital as opposed to another (i.e., the same child would have had a $62 \%$ higher chance of death if he/she had been admitted to a different randomly selected hospital). In a similar model with the same patient- and hospital-level covariates but that lacked the hospital-specific ICP monitoring rate, the proportional change in interhospital variance in pediatric TBI mortality after adding the hospital-specific ICP monitoring rate was $-15.9 \%$. In other words, $15.9 \%$ of the interhospital variation in pediatric TBI mortality could be attributed to variability in hospital-specific ICP monitoring use.

\section{Sensitivity Analysis}

To examine the association between ICP monitoring use and mortality among subjects who were more similar to each other, we used the propensity score-matching method to reanalyze the data. Propensity score matching generated 261 distinct pairs $(n=522)$. Within the matched cohort, patient and hospital characteristics were well balanced (Table S2 in the Supplementary Appendix). After matching, ICP monitoring was associated with lower inhospital mortality among children with severe TBI (28 vs 45 deaths; OR 0.62; 95\% CI 0.40-0.96; $p=0.03$ ). Further details are provided in the Supplementary Appendix.

\section{Discussion}

The findings of this observational study suggest that the use of ICP monitoring among children with severe TBI is associated with lower in-hospital mortality at the patient level. The results were consistent when we examined this association at the hospital level. Hospitals with higher rates of ICP monitoring use among children with severe TBI have better outcomes after adjusting for case mix. Furthermore, the variability in rates of ICP monitoring use across different hospitals explained a modest fraction of the interhospital variability in pediatric TBI mortality.

Previous studies have shown that children with severe TBI are at substantial risk for intracranial hypertension, which is independently associated with higher mortality and poor functional outcome. Furthermore, no specific markers have been identified that reliably determine the presence or absence of intracranial hypertension without invasive monitoring in this population. Therefore, continuous ICP monitoring via an invasive tool is considered by many to be a valuable means for the early detection of elevated ICP, which may facilitate prompter treatment to control the rising pressure inside the rigid skull. Based on 
TABLE 1. Baseline characteristics of patients who were managed with or without ICP monitoring*

\begin{tabular}{|c|c|c|c|}
\hline Characteristic & ICP Group, 273 Patients & No-ICP Group, 1432 Patients & Standardized Difference $†$ \\
\hline \multicolumn{4}{|l|}{ Patient-level } \\
\hline Age in yrs, median (IQR) & $9(3-14)$ & $8(3-14)$ & 0.10 \\
\hline Age category & & & 0.10 \\
\hline$<1 \mathrm{yr}$ & $16(5.9)$ & $114(7.96)$ & \\
\hline $1-4$ yrs & $74(27.11)$ & $381(26.61)$ & \\
\hline $5-9$ yrs & $50(18.32)$ & $290(20.25)$ & \\
\hline $10-14$ yrs & $65(23.81)$ & $366(25.56)$ & \\
\hline $15-16$ yrs & $68(24.91)$ & $281(19.62)$ & \\
\hline \multicolumn{4}{|l|}{ Sex } \\
\hline Female & $87(31.87)$ & $488(34.08)$ & 0.05 \\
\hline Race & & & 0.05 \\
\hline Black & $44(16.12)$ & $259(18.09)$ & \\
\hline White & $167(61.17)$ & $862(60.20)$ & \\
\hline Other & $48(17.58)$ & $243(16.97)$ & \\
\hline Unknown/missing & $14(5.13)$ & $68(4.75)$ & \\
\hline AIS Head score & & & 0.48 \\
\hline 3 & $21(7.69)$ & $309(21.58)$ & \\
\hline 4 & $123(45.05)$ & $697(48.67)$ & \\
\hline 5 & $129(47.25)$ & $426(29.75)$ & \\
\hline \multicolumn{4}{|l|}{ Intracranial lesion } \\
\hline Epidural hematoma & $44(16.12)$ & $203(14.18)$ & 0.05 \\
\hline Subdural hematoma & $140(51.28)$ & $558(38.97)$ & 0.25 \\
\hline Traumatic subarachnoid hemorrhage & $97(35.53)$ & $396(27.65)$ & 0.17 \\
\hline Intracerebral mass lesion & $13(4.76)$ & $27(1.89)$ & 0.16 \\
\hline Compressed/absent basal cisterns & $7(2.56)$ & $11(0.77)$ & 0.14 \\
\hline Brainstem/cerebellar lesion & $34(12.45)$ & $135(9.43)$ & 0.10 \\
\hline Hypotension, age adjusted & $24(8.8)$ & $210(14.7)$ & 0.18 \\
\hline Missing SBP value & $5(1.83)$ & $40(2.79)$ & \\
\hline Motor GCS score, median (IQR) & $1(1-3)$ & $1(1-2)$ & 0.08 \\
\hline Missing motor GCS score & $5(1.83)$ & $24(1.68)$ & \\
\hline Mechanism & & & 0.12 \\
\hline Fall & $67(24.54)$ & $394(27.51)$ & \\
\hline Motor vehicle collision & $74(27.11)$ & $399(27.86)$ & \\
\hline Motorcycle & $5(1.83)$ & $15(1.05)$ & \\
\hline Pedestrian & $59(21.61)$ & $259(18.09)$ & \\
\hline Other & $68(24.91)$ & $365(25.49)$ & \\
\hline Type of insurance & & & 0.07 \\
\hline Commercial & $112(41.03)$ & $557(38.90)$ & \\
\hline Noncommercial & $139(50.92)$ & 775 (54.12) & \\
\hline Unknown & $22(8.06)$ & $100(6.98)$ & \\
\hline \multicolumn{4}{|l|}{ Hospital-level } \\
\hline Trauma center type & & & 0.20 \\
\hline Adult & $111(40.66)$ & $521(36.38)$ & \\
\hline Mixed & $108(39.56)$ & $508(35.47)$ & \\
\hline Pediatric & $54(19.78)$ & $403(28.14)$ & \\
\hline Trauma center level & & & 0.07 \\
\hline Level I & $172(63.00)$ & $855(59.71)$ & \\
\hline Level II & $101(37.00)$ & $577(40.29)$ & \\
\hline
\end{tabular}


TABLE 1. Baseline characteristics of patients who were managed with or without ICP monitoring* (continued)

\begin{tabular}{|c|c|c|c|}
\hline Characteristic & ICP Group, 273 Patients & No-ICP Group, 1432 Patients & Standardized Difference $†$ \\
\hline \multicolumn{4}{|l|}{ Hospital-level (continued) } \\
\hline Vol of pediatric TBI patients & & & 0.15 \\
\hline Quartile $1,<10$ patients & $70(25.64)$ & $319(22.28)$ & \\
\hline Quartile 2, 10-17 patients & $54(19.78)$ & $233(16.27)$ & \\
\hline Quartile 3, 18-25 patients & $60(21.98)$ & $308(21.51)$ & \\
\hline Quartile 4, >25 patients & $89(32.60)$ & $572(39.94)$ & \\
\hline Hospital type & & & 0.00 \\
\hline Nonprofit & $263(96.34)$ & $1380(96.37)$ & \\
\hline For profit & $10(3.66)$ & $52(3.63)$ & \\
\hline No. of beds & & & 0.08 \\
\hline$\leq 200$ & $11(4.03)$ & $44(3.07)$ & \\
\hline $201-400$ & $82(30.04)$ & $408(28.49)$ & \\
\hline $401-600$ & $79(28.94)$ & $399(27.86)$ & \\
\hline$>600$ & $101(37.00)$ & $581(40.57)$ & \\
\hline Teaching status & & & 0.11 \\
\hline University & $181(66.30)$ & $1021(71.30)$ & \\
\hline Community & 79 (28.94) & $359(25.07)$ & \\
\hline Nonteaching & $13(4.76)$ & $52(3.63)$ & \\
\hline
\end{tabular}

this indirect evidence, ICP monitoring was recommended by the Brain Trauma Foundation guidelines as part of the acute management of pediatric severe TBI. ${ }^{22}$ However, recent studies have shown large variation in the use of ICP monitoring technology among centers caring for children with severe TBI. ${ }^{9,39}$ Variable conformance with the guidelines in practice probably reflects the paucity of available data from well-designed studies to support the effectiveness of ICP monitoring use in improving outcomes among children with severe TBI. ${ }^{15,20}$

Our findings agree with those of a previous study, demonstrating that hospitals that monitor ICP more frequently have better pediatric TBI outcomes. ${ }^{9}$ Our results, however, contrast with several studies showing no association between ICP monitoring use and improved outcomes. ${ }^{30,35,39}$ Previous studies of ICP monitoring in the pediatric TBI population have generally had several limitations, including small sample size, a lack of or inadequate adjustment for multiple important confounders, and selection bias. . $^{10,12,26,30,35,39}$ In addition, the clustering of ICP-management strategies for TBI at different hospitals is possible and may also lead to clustering of patient outcomes. The potential for clustering is often not accounted for during statistical analysis in multicenter pediatric TBI studies. ${ }^{39}$

In addition to the large sample size from a homogeneous population, the strengths of our study include the use of multiple approaches and statistical techniques to examine the association between ICP monitoring and pediatric TBI mortality (accounting for the hierarchical structure of the data during statistical analysis) and the adjustment for multiple important patient- and hospital- level confounders. Several limitations should be considered when interpreting our findings. The source database did not contain certain clinical variables that may influence the decision to insert an ICP monitor, such as physician judgment, changes in physiological variables, patient progress during hospital stay, and whether TBI was intentional or accidental. These deficiencies render the findings vulnerable to bias due to unmeasured confounding. To attempt to address this limitation, we asked a second question: Do centers with higher rates of ICP monitoring use have lower pediatric TBI mortality? To answer this question, we repeated the analysis with the exposure being ICP monitoring use as a hospital-level factor in addition to adding an extra term to account for the random differences in TBI mortality among different hospitals by using a random-intercept multilevel model. Furthermore, we matched patients who were similar in terms of propensity scores (representing the probability that patients would be selected for ICP monitoring) to obtain a well-balanced cohort and minimize selection bias. Each of these analytical approaches provided results that support the benefit of using ICP monitoring among children with severe TBI. Nonetheless, we cannot completely rule out the possibility that the reported associations are due to random chance, despite the use of multiple sophisticated statistical techniques. Randomized trials are the only definitive way to address unmeasured confounding.

Ideally, the occurrence of complications after discharge from the hospital, especially death, should be captured in studies of the TBI population to understand the late effects of disease and treatment. However, prior studies of the nat- 
TABLE 2. Baseline characteristics of patients within strata based on hospital-specific rate of ICP-monitoring use*

\begin{tabular}{|c|c|c|c|}
\hline \multirow[b]{2}{*}{ Characteristic } & \multicolumn{2}{|c|}{ Hospital ICP Rate } & \multirow[b]{2}{*}{ Standardized Difference $†$} \\
\hline & High, 956 Patients & Low, 749 Patients & \\
\hline ICP monitoring & $254(26.6)$ & $19(2.5)$ & 0.72 \\
\hline \multicolumn{4}{|l|}{ Patient-level } \\
\hline Age in yrs, median (IQR) & $8(3-14)$ & $9(3-14)$ & 0.13 \\
\hline Age category & & & 0.13 \\
\hline$<1 \mathrm{yr}$ & $79(8.26)$ & $51(6.81)$ & \\
\hline $1-4 \mathrm{yrs}$ & $258(26.99)$ & $197(26.30)$ & \\
\hline $5-9$ yrs & $209(21.86)$ & $131(17.49)$ & \\
\hline $10-14$ yrs & $239(25.00)$ & $192(25.63)$ & \\
\hline $15-16$ yrs & $171(17.89)$ & $178(23.77)$ & \\
\hline \multicolumn{4}{|l|}{ Sex } \\
\hline Female & $327(34.21)$ & $248(33.11)$ & 0.02 \\
\hline Race & & & 0.31 \\
\hline Black & $152(15.90)$ & $151(20.16)$ & \\
\hline White & $544(56.90)$ & $485(64.75)$ & \\
\hline Other & $208(21.76)$ & $83(11.08)$ & \\
\hline Unknown/missing & $52(5.44)$ & $30(4.01)$ & \\
\hline AIS Head score & & & 0.07 \\
\hline 3 & $178(18.62)$ & $152(20.29)$ & \\
\hline 4 & $456(47.70)$ & $364(48.60)$ & \\
\hline 5 & $322(33.68)$ & 233 (31.11) & \\
\hline \multicolumn{4}{|l|}{ Intracranial lesion } \\
\hline Epidural hematoma & $142(14.85)$ & $105(14.02)$ & 0.02 \\
\hline Subdural hematoma & $391(40.90)$ & $307(40.99)$ & 0.00 \\
\hline Traumatic subarachnoid hemorrhage & $284(29.71)$ & $209(27.90)$ & 0.04 \\
\hline Intracerebral mass lesion & $26(2.72)$ & $14(1.87)$ & 0.06 \\
\hline Compressed/absent basal cisterns & $13(1.36)$ & $5(0.67)$ & 0.07 \\
\hline Brainstem/cerebellar lesion & $98(10.25)$ & $71(9.48)$ & 0.03 \\
\hline Hypotension, age adjusted & $128(13.4)$ & $106(14.2)$ & 0.02 \\
\hline Missing SBP value & $25(2.62)$ & $20(2.67)$ & \\
\hline Motor GCS score, median (IQR) & $1(1-3)$ & $1(1-2)$ & 0.04 \\
\hline Missing motor GCS score & $18(1.88)$ & $11(1.47)$ & \\
\hline Mechanism & & & 0.14 \\
\hline Fall & $269(28.14)$ & $192(25.63)$ & \\
\hline Motor vehicle collision & $240(25.10)$ & $233(31.11)$ & \\
\hline Motorcycle & $11(1.15)$ & $9(1.20)$ & \\
\hline Pedestrian & $181(18.93)$ & $137(18.29)$ & \\
\hline Other & $255(26.67)$ & $178(23.77)$ & \\
\hline Type of insurance & & & 0.16 \\
\hline Commercial & $352(36.82)$ & $317(42.32)$ & \\
\hline Noncommercial & $521(54.50)$ & $393(52.47)$ & \\
\hline Unknown & $83(8.68)$ & $39(5.21)$ & \\
\hline \multicolumn{4}{|l|}{ Hospital-level } \\
\hline Trauma center type & & & 0.20 \\
\hline Adult & $360(37.66)$ & $272(36.32)$ & \\
\hline Mixed & $375(39.23)$ & $241(32.18)$ & \\
\hline Pediatric & $221(23.12)$ & $236(31.51)$ & \\
\hline
\end{tabular}


TABLE 2. Baseline characteristics of patients within strata based on hospital-specific rate of ICP-monitoring use* (continued)

\begin{tabular}{|c|c|c|c|}
\hline \multirow[b]{2}{*}{ Characteristic } & \multicolumn{2}{|c|}{ Hospital ICP Rate } & \multirow[b]{2}{*}{ Standardized Difference $\dagger$} \\
\hline & High, 956 Patients & Low, 749 Patients & \\
\hline \multicolumn{4}{|l|}{ Hospital-level (continued) } \\
\hline Trauma center type & & & 0.20 \\
\hline Adult & $360(37.66)$ & $272(36.32)$ & \\
\hline Mixed & $375(39.23)$ & $241(32.18)$ & \\
\hline Pediatric & $221(23.12)$ & $236(31.51)$ & \\
\hline Trauma center level & & & 0.02 \\
\hline Level I & $579(60.56)$ & $448(59.81)$ & \\
\hline Level II & $377(39.44)$ & $301(40.19)$ & \\
\hline Vol of pediatric TBI patients & & & 0.06 \\
\hline Quartile 1, <10 patients & $222(23.22)$ & $167(22.30)$ & \\
\hline Quartile 2, 10-17 patients & $152(15.90)$ & $135(18.02)$ & \\
\hline Quartile 3, 18-25 patients & $236(24.69)$ & $132(17.62)$ & \\
\hline Quartile 4, >25 patients & $346(36.19)$ & $315(42.06)$ & \\
\hline Hospital type & & & 0.02 \\
\hline Nonprofit & $923(96.55)$ & $720(96.13)$ & \\
\hline For profit & $33(3.45)$ & $29(3.87)$ & \\
\hline No. of beds & & & 0.13 \\
\hline$\leq 200$ & $39(4.08)$ & $16(2.14)$ & \\
\hline $201-400$ & $267(27.93)$ & $223(29.77)$ & \\
\hline $401-600$ & $259(27.09)$ & $219(29.24)$ & \\
\hline$>600$ & $391(40.90)$ & $291(38.85)$ & \\
\hline Teaching status & & & 0.13 \\
\hline University & $653(68.31)$ & $549(73.30)$ & \\
\hline Community & $269(28.14)$ & $169(22.56)$ & \\
\hline Nonteaching & $34(3.56)$ & $31(4.14)$ & \\
\hline
\end{tabular}

* With the exception of the standardized difference column, values are expressed as number of patients (\%) unless otherwise specified.

$\dagger$ Standardized difference $>0.10$ is considered meaningful.

ural history of hospitalized TBI patients have suggested that TBI-attributable deaths after hospital discharge are uncommon. ${ }^{36}$ This observation suggests that short-term survival end points might be more efficient, although not ideal, for detecting treatment differences among clinical studies involving patients with severe TBI. Limited by the database, we could not assess the relationship between ICP monitoring and other outcome measures, including longterm functional and quality-of-life outcomes. Future studies are required to examine these important relationships.

In our cohort, there was no significant interaction between ICP monitoring and age. However, because of the low number of subjects in certain age strata in our cohort, we cannot rule out the possibility that the association between ICP monitoring and lower mortality varies depending on patient age. Future studies need to explore the value of ICP monitoring among certain pediatric subgroups, such as infants with open fontanelles and sutures.

Our study showed substantial unexplained variation in the mortality of children with severe TBI among different hospitals. Future studies should examine other institutional practices and organizational structures that may contribute to this variation in pediatric TBI outcome.
Pending further well-designed observational studies or randomized trials, our study suggests that wider use of ICP monitoring technology in the management of children with severe TBI appears warranted to better inform clinical decisions and guide prompter interventions.

\section{Conclusions}

In this observational study, ICP monitoring use was associated with lower hospital mortality at both the patient and hospital levels. However, the contribution of variable ICP monitoring rates to interhospital variation in pediatric TBI mortality was modest. Other institutional practices that may contribute to this variation should be explored in future research.

\section{References}

1. Adelson PD, Bratton SL, Carney NA, Chesnut RM, du Coudray HE, Goldstein B, et al: Guidelines for the acute medical management of severe traumatic brain injury in infants, children, and adolescents. Chapter 7. Intracranial pressure monitoring technology. Pediatr Crit Care Med 4 (3 Suppl):S28S30, 2003 
2. Alberico AM, Ward JD, Choi SC, Marmarou A, Young HF: Outcome after severe head injury. Relationship to mass lesions, diffuse injury, and ICP course in pediatric and adult patients. J Neurosurg 67:648-656, 1987

3. Anderson VA, Catroppa C, Haritou F, Morse S, Rosenfeld JV: Identifying factors contributing to child and family outcome 30 months after traumatic brain injury in children. $\mathbf{J}$ Neurol Neurosurg Psychiatry 76:401-408, 2005

4. Austin PC: An introduction to propensity score methods for reducing the effects of confounding in observational studies. Multivariate Behav Res 46:399-424, 2011

5. Austin PC: Optimal caliper widths for propensity-score matching when estimating differences in means and differences in proportions in observational studies. Pharm Stat 10:150-161, 2011

6. Austin PC: Propensity-score matching in the cardiovascular surgery literature from 2004 to 2006: a systematic review and suggestions for improvement. J Thorac Cardiovasc Surg 134:1128-1135, 2007

7. Austin PC: Using the standardized difference to compare the prevalence of a binary variable between two groups in observational research. Comm Stat Simul Comput 38:1228 1234, 2009

8. Barzilay Z, Augarten A, Sagy M, Shahar E, Yahav Y, Boichis $\mathrm{H}$ : Variables affecting outcome from severe brain injury in children. Intensive Care Med 14:417-421, 1988

9. Bennett TD, Riva-Cambrin J, Keenan HT, Korgenski EK, Bratton SL: Variation in intracranial pressure monitoring and outcomes in pediatric traumatic brain injury. Arch Pediatr Adolesc Med 166:641-647, 2012

10. Chesnut RM: Intracranial pressure monitoring in braininjured patients is associated with worsening of survival. J Trauma 65:500-501, 2008

11. Chesnut RM, Marshall LF, Klauber MR, Blunt BA, Baldwin $\mathrm{N}$, Eisenberg HM, et al: The role of secondary brain injury in determining outcome from severe head injury. J Trauma 34:216-222, 1993

12. Citerio G, Stocchetti N: Intracranial pressure and outcome in severe traumatic brain injury: the quest for evidence continues. Intensive Care Med 34:1173-1174, 2008

13. Committee on Injury Scaling: The Abbreviated Injury Scale, 1998 Revision (AIS-98). Des Plaines, IL: Association for the Advancement of Automotive Medicine, 1998

14. Coronado VG, Xu L, Basavaraju SV, McGuire LC, Wald MM, Faul MD, et al: Surveillance for traumatic brain injuryrelated deaths-United States, 1997-2007. MMWR Surveill Summ 60:1-32, 2011

15. Dean NP, Boslaugh S, Adelson PD, Pineda JA, Leonard JR: Physician agreement with evidence-based recommendations for the treatment of severe traumatic brain injury in children. J Neurosurg 107 (5 Suppl):387-391, 2007

16. Hemmila MR, Nathens AB, Shafi S, Calland JF, Clark DE, Cryer HG, et al: The Trauma Quality Improvement Program: pilot study and initial demonstration of feasibility. J Trauma 68:253-262, 2010

17. Hovda DA, Becker DP, Katayama Y: Secondary injury and acidosis. J Neurotrauma 9 (Suppl 1):S47-S60, 1992

18. Jagannathan J, Okonkwo DO, Yeoh HK, Dumont AS, Saulle D, Haizlip J, et al: Long-term outcomes and prognostic factors in pediatric patients with severe traumatic brain injury and elevated intracranial pressure. J Neurosurg Pediatr 2:240-249, 2008

19. Katayama Y, Becker DP, Tamura T, Hovda DA: Massive increases in extracellular potassium and the indiscriminate release of glutamate following concussive brain injury. $\mathbf{J}$ Neurosurg 73:889-900, 1990

20. Keenan HT, Nocera M, Bratton SL: Frequency of intracranial pressure monitoring in infants and young toddlers with traumatic brain injury. Pediatr Crit Care Med 6:537-541, 2005
21. Kleinman ME, Chameides L, Schexnayder SM, Samson RA, Hazinski MF, Atkins DL, et al: Part 14: pediatric advanced life support: 2010 American Heart Association Guidelines for Cardiopulmonary Resuscitation and Emergency Cardiovascular Care. Circulation 122 (18 Suppl 3):S876-S908, 2010

22. Kochanek PM, Carney N, Adelson PD, Ashwal S, Bell MJ, Bratton S, et al: Guidelines for the acute medical management of severe traumatic brain injury in infants, children, and adolescents - second edition. Pediatr Crit Care Med 13 (Suppl 1):S1-S82, 2012

23. Kozar RA, Holcomb JB, Xiong W, Nathens AB: Are all deaths recorded equally? The impact of hospice care on riskadjusted mortality. J Trauma Acute Care Surg 76:634-641, 2014

24. Langlois JA: Traumatic Brain Injury in the United States: Assessing Outcomes in Children. Atlanta: National Center for Injury Prevention and Control, Centers for Disease Control and Prevention, 2000

25. Larsen K, Merlo J: Appropriate assessment of neighborhood effects on individual health: integrating random and fixed effects in multilevel logistic regression. Am J Epidemiol 161:81-88, 2005

26. Maas AI, Schouten JW, Stocchetti N, Bullock R, Ghajar J: Questioning the value of intracranial pressure (ICP) monitoring in patients with brain injuries. J Trauma 65:966-967, 2008

27. Mamdani M, Sykora K, Li P, Normand SL, Streiner DL, Austin PC, et al: Reader's guide to critical appraisal of cohort studies: 2. Assessing potential for confounding. BMJ 330:960-962, 2005

28. Merlo J, Chaix B, Ohlsson H, Beckman A, Johnell K, Hjerpe $\mathrm{P}$, et al: A brief conceptual tutorial of multilevel analysis in social epidemiology: using measures of clustering in multilevel logistic regression to investigate contextual phenomena. J Epidemiol Community Health 60:290-297, 2006

29. Merlo J, Yang M, Chaix B, Lynch J, Råstam L: A brief conceptual tutorial on multilevel analysis in social epidemiology: investigating contextual phenomena in different groups of people. J Epidemiol Community Health 59:729-736, 2005

30. Michaud LJ, Rivara FP, Grady MS, Reay DT: Predictors of survival and severity of disability after severe brain injury in children. Neurosurgery 31:254-264, 1992

31. Mickey RM, Greenland S: The impact of confounder selection criteria on effect estimation. Am J Epidemiol 129:125137, 1989

32. O'Brien RM: A caution regarding rules of thumb for variance inflation factors. Qual Quant 41:673-690, 2007

33. Oyetunji TA, Crompton JG, Ehanire ID, Stevens KA, Efron DT, Haut ER, et al: Multiple imputation in trauma disparity research. J Surg Res 165:e37-e41, 2011

34. Parsons LS: Reducing bias in a propensity score matchedpair sample using greedy matching techniques. Presented at SAS Users Group International 26, Long Beach, California, 2001 (Poster) (http://www2.sas.com/proceedings/sugi26/ p214-26.pdf) [Accessed May 28, 2015]

35. Pfenninger J, Santi A: Severe traumatic brain injury in children-are the results improving? Swiss Med Wkly 132:116120,2002

36. Selassie AW, McCarthy ML, Ferguson PL, Tian J, Langlois JA: Risk of posthospitalization mortality among persons with traumatic brain injury, South Carolina 1999-2001. J Head Trauma Rehabil 20:257-269, 2005

37. Shafi S, Nathens AB, Cryer HG, Hemmila MR, Pasquale MD, Clark DE, et al: The Trauma Quality Improvement Program of the American College of Surgeons Committee on Trauma. J Am Coll Surg 209:521-530, 530.e1, 2009

38. Shahlaie K, Zwienenberg-Lee M, Muizelaar JP: Clinical pathophysiology of traumatic brain injury, in Winn HR (ed): 
Youmans Neurological Surgery, ed 6. Philadelphia: Saunders, 2011, Vol 4, pp 3362-3379

39. Tilford JM, Simpson PM, Yeh TS, Lensing S, Aitken ME, Green JW, et al: Variation in therapy and outcome for pediatric head trauma patients. Crit Care Med 29:1056-1061, 2001

40. Wijeysundera DN, Austin PC, Beattie WS, Hux JE, Laupacis A: Variation in the practice of preoperative medical consultation for major elective noncardiac surgery: a populationbased study. Anesthesiology 116:25-34, 2012

\section{Disclosures}

This work was supported in part by funds from a Canada Research Chair Program in Systems of Trauma Care (to Dr. Nathens). No competing financial interests exist.

\section{Author Contributions}

Conception and design: Alali, Gomez, Burd, Nathens. Acquisition of data: Alali, Sathya, Nathens. Analysis and interpreta- tion of data: Alali, Gomez, Sathya, Burd, Mainprize, Moulton, Falcone, Nathens. Drafting the article: Alali, Gomez, Burd, Mainprize, Nathens. Critically revising the article: all authors. Reviewed submitted version of manuscript: all authors. Approved the final version of the manuscript on behalf of all authors: Alali. Statistical analysis: Alali. Administrative/technical/material support: Nathens. Study supervision: Nathens.

\section{Supplemental Information}

Online-Only Content

Supplemental material is available with the online version of the article.

Supplementary Appendix. http://thejns.org/doi/suppl/10.3171/ 2015.3.PEDS14507.

\section{Correspondence}

Aziz S. Alali, Sunnybrook Research Institute, 2075 Bayview Ave., Rm. D-574, Toronto, ON M4N 3M5, Canada. email: aziz. alali@mail.utoronto.ca. 